УДК 621.891

\title{
ИНТЕГРАЛЬНЫЙ ПАРАМЕТР ОЦЕНКИ ТРИБОЛОГИЧЕСКИХ СВОЙСТВ СМАЗОЧНЫХ МАТЕРИАЛОВ
}

Др техн. наук В.А. Войтов, аспид. М.Б. Захарченко

\section{ІНТЕГРАЛЬНИЙ ПАРАМЕТР ОЦІНКИ ТРИБОЛОГІЧНИХ ВЛАСТИВОСТЕЙ МАСТИЛЬНИХ МАТЕРІАЛІВ}

Д-р техн. наук В.А. Войтов, аспір. М.Б. Захарченко

\section{INTEGRAL PARAMETER ESTIMATION OF THE TRIBOLOGICAL PROPERTIES OF LUBRICANTS}

\section{Doctor of Technical SciencesV.A. Vojtov, a graduate student}

\section{M.B. Zakharchenko}

В работе предложен энергетический параметр - удельная работа изнашивания тестового материала в испытуемой смазочной среде, который связан с работой трения на удаление объема материала с поверхности трения. Указанный параметр оценивает диапазон работы противоизносных и противозадирных присадок в смазочном материале $и$ позволяет дифференщировать эффективность противоизносных и противозадирных присадок. На основании проведенных экспериментальных исследований по оценке трибологических свойств смазочных материалов и рабочих жидкостей различного назначения сделан вывод, что в математических моделях по расчету скорости изнашивания и коэффициента трения необходимо использовать интегральный показатель, который является более чувствительной характеристикой по сравнению с другими параметрами и базируется на энергетических теориях трения и изнашивания.

Ключевые слова: трибологические свойства, удельная работа изнашивания, моторные масла, трансмиссионные масла.

У роботі запропоновано енергетичний параметр - питома робота зношування тестового матеріалу в випробуваному мастильному середовищі, який пов'язаний з роботою тертя на видалення обсягу матеріалу з поверхні тертя. Зазначений параметр оцінює діапазон роботи протизносних $i$ протизадирних присадок в змашувальному матеріалі $i$ дозволяє диференціювати ефективність протизносних і присадок. На підставі проведених експериментальних досліджень з оцінки трібологічних властивостей мастильних матеріалів і робочих рідин різного призначення зроблено висновок, щзо в математичних моделях за розрахунком швидкості зношування $i$ коефіиієнта тертя необхідно використовувати інтегральний показник, який $є$ більш чутливою характеристикою в порівнянні з іншими параметрами $і$ базується на енергетичних теоріях тертя $i$ зношування.

Ключові слова: трібологічні властивості, питома робота зношування, моторні оливи, трансмісійні оливи.

The paper proposes an energy parameter - the specific work wear test material in the test lubricant medium which is associated with the work to remove the amount of friction material from a friction surface. This parameter estimates the range of the antiwear and additives in the lubricant and allows us to differentiate the effectiveness of anti-wear and extreme pressure additives. On the basis of experimental studies to evaluate the tribological properties of 
lubricants and fluids for different purposes concluded that in mathematical models for calculation of wear rate and friction coefficient is necessary to use an integral index, which is more sensitive characteristic compared to other parameters, and based on energy theory friction and wear.

Key words: tribological properties, specific work wear, engine oils, gear oils.

Актуальность. $\quad$ Трибологические свойства смазочной среды не могут рассматриваться в отрыве от материалов узла трения, а, следовательно, их выбор в трибосистему должен осуществляться комплексно. Смазочная среда оказывает большое влияние на совместимость материалов в трибосистеме в процессе эксплуатации, а, следовательно, определяет ресурс и потери на трение. Результатом взаимодействия присадок смазочной среды с материалами поверхностей трения являются процессы физической адсорбции, хемосорбции и химических реакций, которые и влияют на износостойкость трибосистемы.

Анализ последних публикаций по данной проблеме. Согласно ГОСТ 9490-75 "Материалы смазочные. Жидкие и пластичные. Метод определения трибологических характеристик на четырехшариковой машине" характеристики смазочных материалов определяются по черырем параметрам: показатель износа; критическая нагрузка; нагрузка сваривания; индекс задира.

Основываясь на работах [1-5] можно сделать вывод, что показатель износа характеризует наличие в смазочном материале противоизносных свойств, которые, в основном, обеспечиваются поверхностноактивными веществами и их физической адсорбцией к поверхности трения.

Критическая нагрузка характеризует диапазон работы поверхностно-активных веществ, при достижении которого физическая адсорбция молекул смазочного материала к поверхности трения исчезает. Связано это с повышением температуры поверхностей трения. Из этого следует, что критическая нагрузка также определяет противоизносные свойства смазочного материала.

Нагрузка сваривания характеризует противозадирные свойства смазочного материала и их диапазон работы, т.е. наличие в смазочном материале химическиактивных веществ и их способность вступать в реакцию с материалами поверхностей трения.
Четвертый показатель - индекс задира, является интегральной характеристикой смазочного материала, однако характеризует противозадирные свойства.

Авторами работ $[1,6-8]$ предлагается энергетический параметр - удельная работа изнашивания тестового материала в испытуемой смазочной среде, который связан с работой трения на удаление объема материала с поверхности трения и может выступать интегральным энергетическим параметром смазывающих свойств. Однако, указанный параметр не оценивает диапазона работы противоизносных и противозадирных присадок в смазочном материале, а следовательно не позволяет дифференцировать эффективность противоизносных и противозадирных присадок.

Целью данного исследования явилось разработка интегрального параметра оценки трибологических свойств смазочной среды с оценкой вклада противоизносных и противозадирных присадок, наличие которого позволит учитывать трибологические свойства смазочных материалов при моделировании процессов трения и изнашивания в трибосистемах в условиях граничной смазки.

Методический подход в проведении исследований. Экспериментальные исследования трибологических свойств смазочных материалов проводились на четырехшариковой машине согласно ГОСТ 9490.

Для выполнения математического моделирования изменения скорости изнашивания и коэффициента трения при использовании различных смазочных материалов были выбраны различные рабочие жидкости и смазочные материалы с целью получения большого диапазона изменения интегрального параметра.

\section{Результаты}

исследований. Трибологические свойства смазочной среды, согласно приведенных выше работ, можно учитывать с помощью параметра $E_{y}$, Дж/м $\mathrm{m}^{3}-$ 
удельная работа изнашивания единицы объема тестового материала (шарики из стали ШХ-15) в испытуемой смазочной

$$
E_{y}=E_{1}+E_{2}+E_{3}=\frac{f_{1} P_{1} L_{1}}{D_{u}^{3}}+\sum_{i=196}^{P_{\kappa}} \frac{f_{i} P_{i} L_{2}}{D_{i}^{3}}+\sum_{j=P_{\kappa}}^{P_{c-1}} \frac{f_{j} P_{j} L_{2}}{D_{j}^{3}},
$$

где $E_{1}$ - величина удельной работы изнашивания, которая характеризует наличие противоизносных свойств в смазочном материале, Дж/м³

$E_{2}$ - величина удельной работы изнашивания, которая характеризует диапазоны работы противоизносных присадок, Дж/ $\mathbf{m}^{3}$;

$E_{3}$ - величина удельной работы изнашивания, которая характеризует наличие в смазочном материале противозадирных присадок и диапазон их работы, Дж/м ${ }^{3}$;

$f_{1}$ - коэффициент трения при нагрузке $\mathrm{P}_{1}=196 \mathrm{H}$;

$P_{1}$ - нагрузка равная $196 \mathrm{H}$ для определения показателя износа на четырехшариковой машине, ГОСТ 9490-75;

$L_{1}-$ путь трения при определении показателя износа, равен 2119 м;

$D_{u}-$ средний диаметр пятен износа трех нижних шариков при определении показателя износа, м;

$$
\sum_{i=196}^{P_{\kappa}} \text { - суммарное значение числа }
$$
испытаний от нагрузки $196 \mathrm{H}$ до критической нагрузки, согласно первого нагрузочного ряда приведенного в ГОСТ 9490;

$f_{i}$ - значения коэффициента трения при нагрузках от $196 \mathrm{H}$ до $\mathrm{P}_{\mathrm{K}}$;

$P_{i}-\quad$ нагрузка согласно первого нагрузочного ряда от $196 \mathrm{H}$ до $\mathrm{P}_{\kappa}, \mathrm{H}$;

$L_{2}-$ путь трения при времени испытания 10 сек, равный 5,88 м;

$D_{i}-$ средний диаметр пятен износа трех нижних шариков при нагрузках от 196 Н до $\mathrm{P}_{\mathrm{K}, \mathrm{M}}$;

$$
\sum_{j=P_{\kappa}}^{P_{c-1}} \text { - суммарное значение числа }
$$

испытаний от $\mathrm{P}_{\kappa}$ до нагрузки, среде. Физический смысл данного параметра следует из выражения:

предшествующей нагрузке сваривания $\mathrm{P}_{\mathrm{C}-1}$;

$f j-$ значение коэффициента трения при нагрузках от $\mathrm{P}_{K}$ до $\mathrm{P}_{\mathrm{C}-1}, \mathrm{H}$;

$D j-$ средний диаметр пятен износа трех нижних шариков при нагрузках от $\mathrm{P}_{K}$ до $\mathrm{P}_{\mathrm{C}-1}$, м.

Отличием формулы (1) от формул приведенных в работах [6-8] является применением суммы значений удельной работы изнашивания на всех нагрузках, от 196 Н до Рк (для второго слагаемого $E_{2}$ ) и от $\mathrm{P}_{K}$ до $\mathrm{P}_{\mathrm{C}-1}$ (для третьего слагаемого $E_{3}$ ). Это дает возможность более точно определить наличие противоизносных и противозадирных свойств в смазочном материале. Например, при одинаковых значениях критической нагрузки, а так же нагрузки сваривания диаметры пятен износа существенно отличаются, что влияет при определении суммы $E_{2}$ и $E_{3}$.

В качестве рабочих жидкостей, которые одновременно выполняют функции смазочных материалов, были выбраны керосин ТC-1 и дизельное топливо, трибологические свойства которых представлены в табл.1.

Трибологические свойства гидравлических масел представлены в таблице 2, моторных масел в таблице 3, трансмиссионных масел в таблице 4.

Обсуждение результатов. Как следует из приведенных таблиц интегральный параметр $E_{y}$ изменяется для топлив в

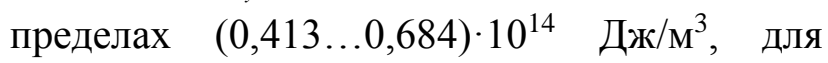
гидравлических масел в пределах $(1,886 \ldots 3,26) 10^{14}$ Дж/м ${ }^{3}$, для моторных масел $(3,209 \ldots 9,411) \quad 10^{14}$ Дж/ $\mathrm{m}^{3}, \quad$ для трансмиссионных масел $(3,64 \ldots 8,79) \cdot 10^{14}$ Дж/ $\mathrm{m}^{3}$.

В таблицах 1 - 4 также представлены трибологические характеристики согласно ГОСТ 9490: показатель износа $D_{u}$; критическая нагрузка $P_{k}$; нагрузка сваривания $P_{c}$ и индекс задира $И_{3}$. Анализ указанных характеристик 
для моторных масел (таблица 3) показывает, что в зависимости от классификации по AРI показатель износа $D_{u}$ отличается на $31 \%$, критическая нагрузка на $P_{k}$ на $37,5 \%$, нагрузка сваривания на $50 \%$, индекс задира на $52 \%$. При этом интегральный показатель трибологических свойств масел отличается на $65 \%$, что подтверждает большую чувствительность Еу по сравнению с показателями согласно ГОСТ 9490.

Наиболее выраженный результат получен для трансмиссионных масел (таблица 4). В зависимости от классификации по АРI показатель износа отличается на $28 \%$, критическая нагрузка на $21 \%$, нагрузка сваривания на 21\%, индекс задира на 19,1\%. При этом интегральный показатель $E_{y}$ изменяется на $58 \%$, что подтверждает большую чувствительность данного показателя. Кроме этого, по величине значений $E_{2}$ и $E_{3}$ можно судить об эффективности противоизносных и противозадирных присадок. Например, эффективность противозадирных присадок для моторных масел, таблица 3, которая

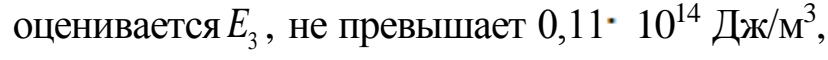
a для трансмиссионных масел, таблица 4, данный показатель равен $0,21^{*} 10^{14}$ Дж/м ${ }^{3}$. Это говорит о том, что трансмиссионные масла имеют более эффективный пакет противозадирных присадок, чем моторные.

Что касается эффективности работы противоизносных присадок, показатель $E_{2}$, то у моторных и трансмиссионных масел наблюдается незначительные отличия.

Выводы. На основании проведенных экспериментальных исследований по оценке трибологических свойств смазочных материалов и рабочих жидкостей различного назначения можно сделать вывод, что в математических моделях по расчету скорости изнашивания и коэффициента трения необходимо использовать интегральный показатель $E_{y}$, который является более чувствительной характеристикой по сравнению с другими параметрами и базируется на энергетических теориях трения и изнашивания.

Трибологические свойства топлив

\begin{tabular}{|c|c|c|c|c|c|c|c|c|}
\hline $\begin{array}{c}\text { Тип } \\
\text { топлива }\end{array}$ & $D_{u}, \mathrm{MM}$ & $P_{k}, \mathrm{H}$ & $P_{c}, \mathrm{H}$ & $\begin{array}{c}И_{3}, \\
\mathrm{H}\end{array}$ & 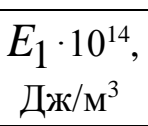 & 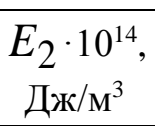 & 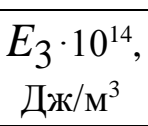 & 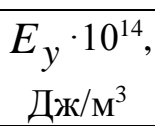 \\
\hline $\begin{array}{l}\text { Керосин } \\
\text { ТС-1 }\end{array}$ & 0,90 & 490 & 784 & 17 & 0,34 & 0,07 & 0,003 & 0,413 \\
\hline $\begin{array}{l}\text { Дизельное } \\
\text { топливо ДТ }\end{array}$ & 0,75 & 617 & 980 & 21 & 0,59 & 0,09 & 0,004 & 0,684 \\
\hline
\end{tabular}

Таблица 2

Трибологические свойства гидравлических масел

\begin{tabular}{|c|c|c|c|c|c|c|c|c|}
\hline $\begin{array}{c}\text { Тип } \\
\text { масел }\end{array}$ & $D_{u}, \mathrm{MM}$ & $P_{k}, \mathrm{H}$ & $P_{c}, \mathrm{H}$ & $U_{3}, \mathrm{H}$ & 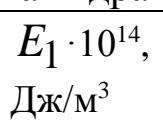 & 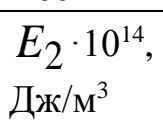 & 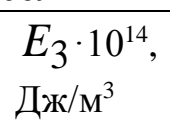 & 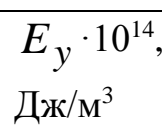 \\
\hline МГП-10 & 0,55 & 710 & 1960 & 24 & 1,5 & 0,38 & 0,006 & 1,886 \\
\hline МГ-15-В & 0,5 & 980 & 1960 & 28 & 1,99 & 0,44 & 0,007 & 2,437 \\
\hline ИГП-30 & 0,5 & 980 & 2450 & 32 & 1,99 & 0,44 & 0,009 & 2,439 \\
\hline МГЕ-46В & 0,45 & 980 & 2450 & 36 & 2,73 & 0,48 & 0,009 & 3,219 \\
\hline МГЕ-68В & 0,45 & 980 & 2450 & 41 & 2,73 & 0,52 & 0,01 & 3,26 \\
\hline
\end{tabular}


Таблица 3

Трибологические свойства моторных масел

\begin{tabular}{|c|c|c|c|c|c|c|c|c|c|}
\hline Тип масла & $\begin{array}{l}\text { Класси- } \\
\text { фикация } \\
\text { по API }\end{array}$ & $\begin{array}{c}D_{u}, \\
\text { мм }\end{array}$ & $\begin{array}{l}P_{k}, \\
\mathrm{H}\end{array}$ & $\begin{array}{l}P_{c}, \\
\mathrm{H}\end{array}$ & $\begin{array}{l}И_{3} \\
\mathrm{H}\end{array}$ & 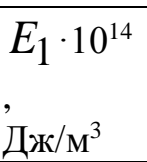 & 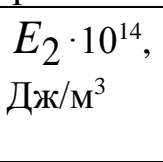 & 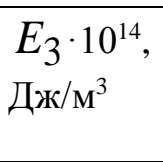 & 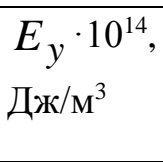 \\
\hline M-10 & $\mathrm{CC}$ & 0,45 & 1235 & 2450 & 28 & 2,73 & 0,47 & 0,009 & 3,209 \\
\hline $\begin{array}{c}\text { Schell-Ro- } \\
\text { tella X }\end{array}$ & $\mathrm{CC}$ & 0,45 & 1235 & 3087 & 32 & 2,73 & 0,82 & 0,094 & 3,644 \\
\hline $\begin{array}{c}\text { ESSO } \\
\text { ULTRA }\end{array}$ & SL/CD & 0,4 & 1568 & 3920 & 59 & 3,89 & 0,99 & 0,012 & 4,892 \\
\hline М-10ДМ & CD & 0,35 & 1568 & 3087 & 49 & 5,82 & 0,9 & 0,11 & 6,830 \\
\hline $\begin{array}{c}\text { Schell- } \\
\text { Rimula D }\end{array}$ & $\mathrm{CF} / \mathrm{CD}$ & 0,35 & 1568 & 3087 & 48 & 5,82 & 0,908 & 0,104 & 6,832 \\
\hline $\begin{array}{c}\text { ESSO } \\
\text { ULTRON }\end{array}$ & SL/CF & 0,35 & 1568 & 4900 & 63 & 5,82 & 0,950 & 0,095 & 6,865 \\
\hline $\begin{array}{c}\text { Schell- } \\
\text { Rimula C }\end{array}$ & $\mathrm{CD}$ & 0,35 & 1568 & 3087 & 48 & 5,82 & 0,96 & 0,090 & 3,870 \\
\hline $\begin{array}{c}\text { Schell- } \\
\text { Rimula X }\end{array}$ & CF-4 & 0,32 & 1235 & 4900 & 63 & 7,62 & 0,85 & 0,014 & 8,484 \\
\hline $\begin{array}{c}\text { ESSO } \\
\text { ULTRA } \\
\text { Turbo Diesel }\end{array}$ & CF-4 & 0,31 & 1568 & 4900 & 64 & 8,39 & 1,005 & 0,016 & 9,411 \\
\hline
\end{tabular}

Таблица 4

Трибологические свойства трансмиссионных масел

\begin{tabular}{|c|c|c|c|c|c|c|c|c|c|}
\hline Тип масла & $\begin{array}{c}\text { Классифи- } \\
\text { кация по } \\
\text { API }\end{array}$ & $\underset{\text { мм }}{D_{u},}$ & $\begin{array}{l}P_{k}, \\
\mathrm{H}\end{array}$ & $\begin{array}{l}P_{c}, \\
\mathrm{H}\end{array}$ & $\begin{array}{l}И_{3} \\
, \mathrm{H}\end{array}$ & 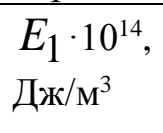 & 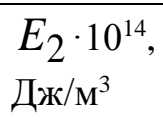 & 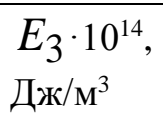 & 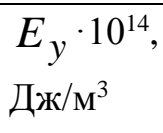 \\
\hline ТСп-10 & GL-4 & 0,45 & 1235 & 6174 & 76 & 2,73 & 0,79 & 0,12 & 3,64 \\
\hline ТАп-15В & GL-4 & 0,45 & 1235 & 6174 & 76 & 2,73 & 0,8 & 0,13 & 3,66 \\
\hline ТСп-15к & GL-4 & 0,40 & 1568 & 6174 & 82 & 3,89 & 0,795 & 0,13 & 4,815 \\
\hline ТСп-14гип & GL-4 & 0,40 & 1235 & 6174 & 82 & 3,89 & 0,802 & 0,14 & 4,832 \\
\hline ТАД-17и & GL-5 & 0,36 & 1568 & 7840 & 89 & 5,34 & 0,885 & 0,114 & 6,369 \\
\hline $\begin{array}{c}\text { Shell- } \\
\text { Spirax-AX }\end{array}$ & GL-5 & 0,35 & 1568 & 7840 & 92 & 5,82 & 0,906 & 0,200 & 6,926 \\
\hline $\begin{array}{c}\text { Shell- } \\
\text { Spirax- } \\
\text { GSX }\end{array}$ & GL-4 & 0,35 & 1568 & 6174 & 86 & 5,82 & 0,945 & 0,200 & 6,965 \\
\hline $\begin{array}{c}\text { VALVOLI } \\
\text { NE }\end{array}$ & GL-5 & 0,34 & 1235 & 6174 & 90 & 6,34 & 0,937 & 0,207 & 7,484 \\
\hline $\begin{array}{c}\text { Shell- } \\
\text { Spirax- } \\
\text { ASX }\end{array}$ & GL-5 & 0,32 & 1568 & 7840 & 94 & 7,62 & 0,960 & 0,210 & 8,79 \\
\hline
\end{tabular}

\section{Список использованных источников}

1. Войтов В.А. Интегральный критерий оценки трибологических свойств смазочных материалов на четырехшариковой машине / В.А Войтов, А.В. Левченко// Трение и износ. 2001, т. 22, №4,c. 441-447.

2. Войтов В.А. Лабораторный метод оценки смазывающих свойств моторных масел на четырехшариковой машине трения / В.А Войтов, А.В. Левченко// Вісник ХДАДТУ, 2002, вип.17, с. $42-48$.

3. Войтов В.А. Критериальный подход для оценки служебных свойств моторных масел в процессе эксплуатации ДВС/ В.А.Войтов, В.А.Мазепа // Вестник НТУ(ХПИ). Сб. 
науч. тр. “Автомобиле- и тракторостроение”.- Харьков: НТУ (ХПИ), 2002, №10,т.1, с.135138.

4. Войтов В.А. Обзор исследований по подбору моторных масел к ДВС и системный подход при его решении / В.А. Войтов, В.А.Мазепа // Вестник ХНТУСХ, 2005, № 40, с.253261.

5. Войтов В.А. Системный подход для эксплуатации моторных масел по техническому состоянию / В.А.Войтов, В.А.Мазепа // Проблеми трибології, 2006, № 1, с.108117.

6. Войтов В.А. Визначення трибологічних властивостей рослинних олій в порівнянні 3 нафтовими оливами / В.А Войтов, А.Г. Кравцов // Вісник ХНТУСГ, 2008, вип. №75, т. 1, с. 382-386.

7. Войтов В.А. Трибологічні властивості технічних олив на базі соняшникової та рапсової олій / В.А Войтов, А.Г. Кравцов // Проблеми трибології, 2011, №4, с. 87-92.

8. Войтов В.А. Трибологические свойства моторных масел для двухтактных двигателей внутреннего сгорания на растительной основе / В. А. Войтов, И. И. Сысенко, А. Г. Кравцов // Проблеми трибології. - 2014. - № 1. - С. 27 - 38.

Войтов Виктор Анатольевич, д.т.н., профессор, заведующий кафедры транспортных технологий и логистики, Харьковский национальный технический университет сельского хозяйства имени П.Василенко. Тел.: (057) 700-38-98 E-mail: ndch_khntusg@ mail.ru

Захарченко Михаил Борисович, аспирант, Харьковский национальный технический университет сельского хозяйства имени П.Василенко. Тел.: 0989160953.

Vojtov V.A. - prof., Kharkiv Petro Vasylenko National Technical University of Agriculture. Tel.: (057) 700-

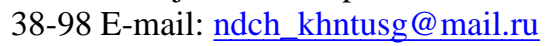

Zakharchenko M., graduate student, Kharkiv Petro Vasylenko National Technical University of Agriculture. Tel.: 0989160953. 